\title{
Localization of the Noncovalent Binding Site Between Amyloid- $\beta$-Peptide and Oleuropein Using Electrospray Ionization FT-ICR Mass Spectrometry
}

\author{
Fotini N. Bazoti, ${ }^{\mathrm{a}, \mathrm{b}}$ Jonas Bergquist, ${ }^{\mathrm{c}}$ Karin Markides, ${ }^{\mathrm{c}}$ and \\ Anthony Tsarbopoulos ${ }^{\mathrm{a}, \mathrm{b}}$ \\ ${ }^{a}$ GAIA Research Center, Bioanalytical Laboratory, The Goulandris Natural History Museum, Kifissia, Greece \\ ${ }^{\mathrm{b}}$ Department of Pharmacy, Laboratory of Instrumental and Pharmaceutical Analysis, University of Patras, \\ Panepistimiopolis, Greece \\ ${ }^{c}$ Department of Analytical Chemistry, Biomedical Centre, Uppsala University, Uppsala, Sweden
}

\begin{abstract}
Abnormal accumulation and aggregation of amyloid- $\beta$-peptide $(\mathrm{A} \beta)$ eventually lead to the formation and cerebral deposition of amyloid plaques, the major pathological hallmark in Alzheimer's disease (AD). Oleuropein (OE), an Olea europaea L. derived polyphenol, exhibits a broad range of pharmacological properties, such as antioxidant, anti-inflammatory, and antiatherogenic, which could serve as combative mechanisms against several reported pathways involved in the pathophysiology of $\mathrm{AD}$. The reported noncovalent interaction between $\mathrm{A} \beta$ and $\mathrm{OE}$ could imply a potential antiamyloidogenic role of the latter on the former via stabilization of its structure and prevention of the adaptation of a toxic $\beta$-sheet conformation. The established $\beta$-sheet conformation of the $\mathrm{A} \beta$ hydrophobic carboxy-terminal region and the dependence of its toxicity and aggregational propensity on its secondary structure make the determination of the binding site between $\mathrm{A} \beta$ and $\mathrm{OE}$ highly important for assessing the role of the interaction. In this study, two different proteolytic digestion protocols, in conjunction with high-sensitivity electrospray ionization mass spectrometric analysis of the resulting peptide fragments, were used to determine the noncovalent binding site of $\mathrm{OE}$ on $\mathrm{A} \beta$ and revealed the critical regions for the interaction. (J Am Soc Mass Spectrom 2008, 19, 1078-1085) (C) 2008 American Society for Mass Spectrometry
\end{abstract}

$\mathrm{A}$ myloid- $\beta$-peptide $(\mathrm{A} \beta)$ is a $39-43$ amino acid peptide characterized by high aggregational propensity and neurotoxicity. It is the central component of the senile plaques in Alzheimer disease (AD) brain [1] and its aggregational properties depend on both the peptide concentration and conformation, as well as on the solution conditions and $\mathrm{pH}[2,3]$. It has been reported that reduction of the $\mathrm{A} \beta$ production, by controlling the cleavage of the larger transmembrane amyloid precursor protein (APP), or inhibition of its aggregation by using small molecules, which may interact noncovalently with $\mathrm{A} \beta$ and stabilize its structure, could serve as preventive or therapeutic approaches against $\mathrm{AD}$ [4]. In general, interruption of noncovalent interactions between protein and peptides, or even more between proteins/peptides and ligands can cause abnormalities, which often lead to diseases [5]. One interaction of this kind has been established between

Address reprint requests to Dr. Anthony Tsarbopoulos, University of Patras, Laboratory of Instrumental Pharmaceutical Analysis, Department of Pharmacy, Panepistimiopolis, 26504 Rio, Greece. E-mail: atsarbop@ upatras.gr the Olea europaea derived bioactive compound, oleuropein $(\mathrm{OE})$, and $\mathrm{A} \beta$ by means of electrospray ionization mass spectrometry (ESI-MS) [6]. This interaction could prove potent in inhibiting its aggregation.

$\mathrm{OE}$ is a polyphenol extracted from the fruits and leaves of Olea europaea L. and possesses a wide range of pharmacological properties, such as antioxidant [7-9], anti-inflammatory [10, 11], antiatherogenic [12-14], antibacterial [15-17], and anticancer [18, 19]. Moreover, $\mathrm{OE}$ and its metabolites have been shown to be potent against contemporary diseases, such as HIV [20,21] and osteoporosis [22, 23]. Interestingly, in vitro [24] and epidemiological [25] studies demonstrated the positive impact of polyphenols on the onset of age-related disorders, such as dementia [26, 27].

It is regarded that the pathophysiology of $\mathrm{AD}$ is tangled and many theories have been proposed to illumine its mechanism. Free radical reactions and oxidative stress [28, 29], as well as unregulated immune response [30,31], are believed to be key factors for the pathogenesis of $\mathrm{AD}$, whereas recent reports suggested a link between heart disease, hypercholesterolemia, and 
AD [32, 33]. Thus, the well-documented antioxidant, anti-inflammatory, and antiatherogenic properties of OE may offer a multistage approach against the diverse mechanisms, which are inherent to AD. This, in conjunction with the ability of $\mathrm{OE}$ to interact with $\mathrm{A} \beta$, thus blocking the peptide in a nontoxic conformation and inhibiting its aggregation, may introduce an ideal regime against its neurotoxicity. However, natural extracts and plants containing antioxidants and phytoestrogens have been involved in the management of cognitive disorders [26], such as $\mathrm{AD}$, and against $\mathrm{A} \beta$-induced toxicity.

Structural and conformational alterations underlying the peptide fibril formation is a multistep reaction involving oligomeric and protofibrillar intermediates [34]. It has been reported that distinct regions of the peptide are responsible for its fibrillation and its subsequent toxicity, especially the carboxy-terminal hydrophobic segment [35]. This region adopts an intermolecular $\beta$-sheet conformation crucial for the oligomerization cascade. It is evident that determination of the noncovalent binding site between $\mathrm{OE}$ and $\mathrm{A} \beta$ would not only increase our understanding of complexation, but would also shed some light into the fibrillization reaction mechanism. Therefore, the goal of the present study is the actual localization of the interaction site between the ligand and the peptide. This is accomplished by enzymatic mapping of the noncovalent complex using two different proteolytic enzymes and the enhanced sensitivity and mass accuracy provided by ESI Fourier transform ion cyclotron (FT-ICR) MS, thus allowing the precise assignment of the binding site. The two proteolytic enzymes used were trypsin and Glu-C, to produce peptide fragments and thus establish the critical peptide regions for the interaction. ESI provides gentle conditions for the transfer of fragile noncovalent interactions in the gas phase and allows their detection by MS, which is optimal for following real-time interactions and probing potential intermediates.

\section{Experimental}

\section{Sample Preparation}

Noncovalent complex monitoring. A $150 \mu \mathrm{L}$ sample of a freshly prepared $\beta$-amyloid peptide, $\mathrm{A} \beta$ (1-40) (Bachem AG, Bubendorf, Switzerland) solution $100 \mu \mathrm{M}(\mathrm{Mr}$ monoisotopic: 4327.15) in deionized water was added to $150 \mu \mathrm{L}$ of an equimolar solution of $\mathrm{OE}$ [Mr monoisotopic: 540.18 isolated from olive leaves of Olea europaea (var. koroneiki), according to a previously described procedure [36] with greater than 99\% purity, as assessed by NMR analysis in $1 \mathrm{mM}$ ammonium acetate (Merck, Darmstad, Germany)-acetic acid (Pancreac, Barcelona, Spain) 0.5\% buffer solution( $\mathrm{pH} 3$ ).

Enzymatic digestion for mapping analysis. Tryptic and Glu-C enzymatic mapping was used to study the interaction site between $\mathrm{A} \beta$ peptide and $\mathrm{OE}$. The $\mathrm{A} \beta$ peptide and its mixtures with the ligand were dissolved in 25
$\mathrm{mM}$ ammonium bicarbonate (Merck) and the $\mathrm{pH}$ of the solution was adjusted to 8.0 with dilute aqueous solution of ammonium hydroxide. Then trypsin (Roche, Mannheim, Germany) or Glu-C (Sigma, St. Louis, MO, USA) was added in 1:100 $\mathrm{M}$ ratio (or $5 \% \mathrm{wt}$ ). The enzymatic reaction was carried out at $37^{\circ} \mathrm{C}$ and quenched after $14 \mathrm{~h}$ by adding $2.5 \%$ acetic acid and deep-freezing of the samples. Similarly, solutions of trypsin and Glu-C were incubated, analyzed, and used as blank samples. All solvents used were of analyticalgrade purity. Post addition of $\mathrm{OE}$ to already digested $\mathrm{A} \beta$ was also performed and the samples were then analyzed by ESI-MS.

Sample desalting. The peptide solutions, the resulting mixtures with $\mathrm{OE}$, and peptide digests thereof were desalted on a ZipTip ${ }_{\mathrm{C} 18}$ pipette tip (Millipore, Billerica, MA, USA) before MS analysis using the following protocol. The tip was first wetted with $3 \times 10 \mu \mathrm{L}$ aqueous acetonitrile solution $50 \%$ and then equilibrated with $3 \times 10 \mu \mathrm{L} 1 \%$ aqueous acetic acid solution. The digest was adsorbed onto the reversed-phase media by 30 repeated cycles of sample loading. The tip was washed with $3 \times 10 \mu \mathrm{L} 1 \%$ acetic acid. Finally, the desalted digests were eluted with $10 \mu \mathrm{L}$ of $50 \%$ acetonitrile in $1 \%$ aqueous acetic acid. This procedure was repeated three times, resulting in a total volume of 30 $\mu \mathrm{L}$ of the eluate. After the desalting, the eluates were directly subjected to ESI FT-ICR MS analysis.

\section{Mass Spectrometry}

All mass spectra were acquired using a Bruker Daltonics (Billerica) BioAPEX-94e superconducting 9.4 T FTICR mass spectrometer [37] in broadband mode. A home-built apparatus controlled the direct infusion of the samples. Helium gas at a pressure of 1.3 bar was used to infuse the sample through a $30 \mathrm{~cm}$ fused-silica capillary with a $50 \mu \mathrm{m}$ inner diameter. One end of the capillary was inserted into the sample and the other one, coated by a conductive graphite/polymer layer of "Black Dust" [38], was connected to ground functioning as a sheathless electrospray needle. No sheath flow or nebulizing gas was used. The flow rate was about 4 $\mathrm{nL} / \mathrm{min}$. The ion source was coupled to an Analytica atmosphere-vacuum interface (Analytica, Branford, CT, USA) and a potential difference of $2.0-3.0 \mathrm{kV}$ was applied across a distance of $3-5 \mathrm{~mm}$ between the spraying needle and the inlet capillary. Typically, 512K data points were acquired, adding a minimum of 128 spectra.

\section{Results and Discussion}

The high resolving power of ESI FT-ICR MS was used to identify the binding site of the $\mathrm{A} \beta-\mathrm{OE}$ noncovalent complex. ESI offers a gentle ionization method optimal for maintaining fragile interactions, such as noncovalent complexes. In addition, the enhanced sensitivity and mass accuracy of FT-ICR make it ideal for conduct- 
ing mapping analyses, providing the localization of the binding site between the ligand and the peptide.

The reported conservation of the $\mathrm{A} \beta$-OE noncovalent interaction even in high content of organic cosolvent $(75 \%$ of $\mathrm{MeOH})$ [6] allows the SPE (ZipTip $\left.{ }_{\mathrm{c} 18}\right)$ purification of the samples before analysis, and also the use of sheathless ESI interface coupled to the FT-ICR analyzer. The increased FT-ICR sensitivity permitted the detection of low-abundance species, even though the ESI conditions are "harder" than those previously used in a triple quadrupole analyzer [6]. Indeed, the $\mathrm{A} \beta-\mathrm{OE}$ noncovalent interaction was confirmed using ESI FT-ICR MS and novel interactions were revealed as well.

ESI-MS analysis of the $\mathrm{A} \beta-\mathrm{OE}$ samples results in "bell-shaped" distributions of multiply charged ions corresponding to $\mathrm{A} \beta$ peptide, its oxidized $\mathrm{A} \beta \operatorname{Met} 35(\mathrm{O})$ and superoxidized $\mathrm{A} \beta \mathrm{Met} 35\left(\mathrm{O}_{2}\right)$ forms, and their corresponding complexes with $\mathrm{OE}$ in various stoichiometries. The noncovalent interaction between $\mathrm{OE}$ and intact $\mathrm{A} \beta$ (1-40) (Figure 1), as well as with its oxidized form $A \beta M e t 35(O)$, possessing an 1:1 stoichiometry, was verified under these conditions. Deconvolution of the spectra gave rise to $4327.19,4343.26,4867.27$, and 4883.49 monoisotopic mass values, which correlate with the theoretical values $4327.16,4343.14,4867.34$, and 4883.33 for $\mathrm{A} \beta$, $\mathrm{A} \beta \operatorname{Met} 35(\mathrm{O}), \mathrm{A} \beta-\mathrm{OE}$, and $\mathrm{A} \beta \operatorname{Met} 35(\mathrm{O})-\mathrm{OE}(1: 1)$, respec- tively. However, the enhanced sensitivity and resolution of FT-ICR MS enabled the detection of $\mathrm{A} \beta$ :OE noncovalent complexes with higher stoichiometries (1: 2 ), albeit at a much lower abundance. The methodology used also allowed the detection of low-abundance oxidized forms of $\mathrm{A} \beta$ [i.e., $\mathrm{A} \beta \operatorname{Met} 35(\mathrm{O})$ and $\mathrm{A} \beta \mathrm{Met} 35\left(\mathrm{O}_{2}\right)$ ] and the $\mathrm{OE}$ 1:1 noncovalent interactions thereof (Table $1)$. The observation of these complexes shows the exceptional importance for an antioxidant such as $\mathrm{OE}$, because it can bind not only to $\mathrm{A} \beta$ and prevent its oxidation and subsequent aggregation, but also to already oxidized species and stop their aggressive progression. Moreover, $\mathrm{OE}$ can interact with $\mathrm{A} \beta$ reactive oxygen species (ROS), deactivate them, and thus protect against their deleterious effect. The theoretical monoisotopic mass values of all the aforementioned species as well as the observed monoisotopic mass values detected are shown in Table 1.

The soft ESI conditions used in this study combined with the analytical strength of the FT-ICR mass analyzer enabled the detection of noncovalent complexes between $\mathrm{A} \beta$ and $\mathrm{OE}$ in stoichiometries 1:1 and 1:2 (Table 1). However, the relative intensity of these species varied, with the $1: 1 \mathrm{~A} \beta: \mathrm{OE}$ noncovalent complex (Figure 1) being the most abundant and the 1:2 A $\beta: \mathrm{OE}$ the least abundant. It has been previously shown from

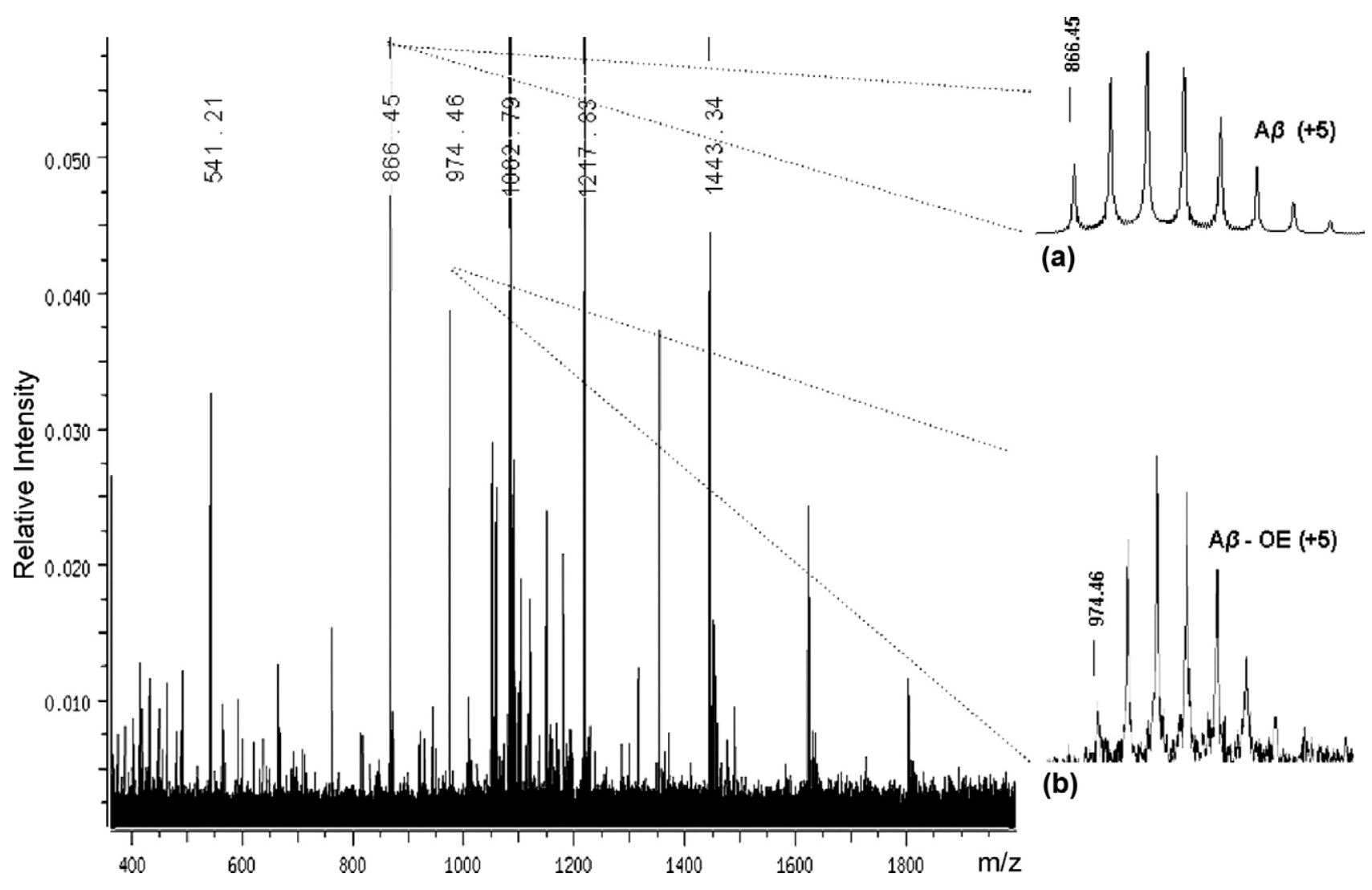

Figure 1. ESI mass spectrum of amyloid- $\beta$-peptide (1-40) in a mixture with oleuropein in a 1:1 molecular ratio, acquired by a 9.4 T FT-ICR analyzer. The magnified regions of the spectrum correspond to (a) the +5 charged ion of $\mathrm{A} \beta(1-40)$ peptide at $\mathrm{m} / \mathrm{z} 866.45$ and (b) the +5 charged ion of the $\mathrm{A} \beta$-OE noncovalent complex at $m / z$ 974.46. 
Table 1. Theoretical and observed mass values of $A \beta$ (1-40) peptide, its oxidized variants, and their potential noncovalent complexes with oleuropein $(\mathrm{OE})^{\mathrm{a}}$

\begin{tabular}{|c|c|c|c|c|c|c|}
\hline \multirow[b]{2}{*}{ Species } & \multicolumn{3}{|c|}{$\begin{array}{l}\text { Monoisotopic theoretical } \\
\text { mass values }\end{array}$} & \multicolumn{3}{|c|}{$\begin{array}{c}\text { Monoisotopic observed } \\
\text { mass values }\end{array}$} \\
\hline & $M_{\mathrm{r}}$ & $(+5)$ & $(+4)$ & $M_{\mathrm{r}}$ & $(+5)$ & $(+4)$ \\
\hline \multicolumn{7}{|l|}{ Peptide } \\
\hline $\mathrm{A} \beta(1-40)$ & 4327.16 & 866.43 & 1082.79 & 4327.19 & 866.45 & 1082.82 \\
\hline \multicolumn{7}{|l|}{ Oxidized peptide } \\
\hline $\mathrm{A} \beta \mathrm{Met} 35(\mathrm{O})$ & 4343.14 & 869.63 & 1086.79 & 4343.26 & 869.65 & 1086.82 \\
\hline $\mathrm{A} \beta \mathrm{Met} 35(\mathrm{O})_{2}$ & 4359.14 & 872.83 & 1090.78 & 4359.34 & 872.88 & 1090.84 \\
\hline \multicolumn{7}{|c|}{ Noncovalent complexes with $\mathrm{OE}$} \\
\hline $\mathrm{A} \beta(1-40)-\mathrm{OE}$ & 4867.34 & 974.47 & 1217.83 & 4867.27 & 974.46 & 1217.88 \\
\hline $\mathrm{A} \beta(1-40)-2 \mathrm{OE}$ & 5407.52 & 1082.50 & 1352.88 & 5407.68 & - & 1352.92 \\
\hline $\mathrm{A} \beta \mathrm{Met} 35(\mathrm{O})-\mathrm{OE}$ & 4883.33 & 977.67 & 1221.83 & 4883.49 & 977.70 & 1221.91 \\
\hline $\mathrm{A} \beta \mathrm{Met} 35(\mathrm{O})_{2}-\mathrm{OE}$ & 4899.32 & 980.86 & 1225.83 & 4899.56 & 980.91 & 1225.89 \\
\hline
\end{tabular}

a The observed mass and $\mathrm{m} / \mathrm{z}$ values of the detected $\mathrm{A} \beta$ species and OE noncovalent complexes thereof are presented in the last three columns.

dilution studies [6] that the interactions are specific and not artifacts of the ESI process. The fact that more than one molecules of $\mathrm{OE}$ can be bound to $\mathrm{A} \beta$ may indicate a protective role of $\mathrm{OE}$ against aggregation. The binding of OE molecules along the peptide's backbone may lock $\mathrm{A} \beta$ 's conformation, thus preventing other molecules of $\mathrm{A} \beta$ to form polymeric species.

Establishment of the specific site of interaction between $\mathrm{OE}$ and $\mathrm{A} \beta$ (1-40) was carried out by using trypsin and Glu-C proteolytic enzymes to gain complementary information on $\mathrm{A} \beta$ sequence. These mapping studies are important, in identifying which region of the peptide interacts with the ligand, and determine whether the hydrophobic segment of $A \beta$ is involved, which is responsible for the $\beta$-sheet intermolecular conformation in aqueous solutions and, consequently, for the neurotoxicity of the peptide. Trypsin cleaves the peptide in almost equal segments of 11-12 residues, except from the first [1-5] fragment. Glu-C cleaves the peptide in fragments of various lengths, but in between the three first fragments derived from the tryptic digestion (Table 2 ). Moreover, two different approaches were attempted: addition of $\mathrm{OE}$ to $\mathrm{A} \beta$ peptide before digestion and addition of $\mathrm{OE}$ to already digested $\mathrm{A} \beta$ peptide. This methodology could prove whether $\mathrm{A} \beta^{\prime}$ s folding is critical for the binding, as well as whether certain residues of $\mathrm{A} \beta$ are critical for the interaction.
Digestion with trypsin yielded the four expected $\mathrm{A} \beta$ fragments: [1-5], [6-16], [17-28], and [29-40] following cleavage after arginine $(\mathrm{R})$ or lysine $(\mathrm{K})$ residues (Table 2 ), as well as partially cleaved fragments (Table 3). The soft ESI ionization also enabled the detection of noncovalent interactions between sequential and nonsequential fragments. Oxidized forms of fragments containing not only the Met35 residue, but also the additional signals corresponding to fragments derived from weak chymotryptic activity (inherent property of trypsin solutions) were also detected in the mass spectra.

Noncovalent interactions of peptide fragments with $\mathrm{OE}$, added before digestion, were detected for the [17-28] fragment of $\mathrm{A} \beta$ (Figure 2) and the partially cleaved peptide fragments [6-28] and [6-40]. In addition, noncovalent complexes of $\mathrm{OE}$ with the [5-19] fragment, derived from the chymotryptic activity of the enzyme, was also detected.

When $\mathrm{OE}$ was added into already digested $\mathrm{A} \beta$ samples with trypsin (Table 3 ), signals corresponding to the following noncovalent interactions were detected: [(17-28)+OE], [(1-16)+OE], [(6-28)+OE], [(6$40)+\mathrm{OE}]$, and $[(17-40)+\mathrm{OE}]$. Oxidized and superoxidized forms of $\mathrm{A} \beta$ tryptic fragments $[(1-16)+(29-$ $40)+\mathrm{O}+\mathrm{OE}]$ and $\left[(1-16)+(29-40)+\mathrm{O}_{2}+\mathrm{OE}\right]$ were found to interact noncovalently with $\mathrm{OE}$, as well as with the chymotryptic $\mathrm{A} \beta$ fragment [5-19].

Table 2. Theoretical and observed mass values of $\mathrm{A} \beta(1-40)$ peptide fragments and their potential noncovalent complexes with oleuropein (OE) following enzymatic digestion with trypsin and Glu-C

\begin{tabular}{|c|c|c|c|c|c|c|}
\hline \multirow[b]{2}{*}{ Enzyme } & \multicolumn{2}{|r|}{ Peptide fragments } & \multirow{2}{*}{$\begin{array}{c}\text { Monoisotopic } \\
\text { A } \beta\end{array}$} & \multirow{2}{*}{$\begin{array}{c}M_{\mathrm{r}} \text { theoretical } \\
\mathrm{A} \beta-\mathrm{OE}\end{array}$} & \multicolumn{2}{|c|}{ Monoisotopic $M_{\mathrm{r}}$ observed } \\
\hline & $\#$ & sequence & & & $\mathrm{A} \beta$ & $\mathrm{A} \beta-\mathrm{OE}$ \\
\hline \multirow[t]{4}{*}{ Trypsin } & {$[1-5]$} & DAEFR & 636.29 & 1176.47 & 636.33 & - \\
\hline & [6-16] & HDSGYEVHHOK & 1335.60 & 1875.78 & 1335.66 & - \\
\hline & [17-28] & LVFFAEDVGSNK & 1324.67 & 1864.85 & 1324.71 & 1864.88 \\
\hline & {$[29-40]$} & GAIIGLMVGGVV & 1084.63 & 1624.81 & 1084.69 & - \\
\hline \multirow[t]{4}{*}{ Glu-C } & {$[1-3]$} & DAE & 333.12 & 873.30 & - & - \\
\hline & [4-11] & FRHDSGYE & 1009.43 & 1549.61 & 1009.47 & 1549.68 \\
\hline & [12-22] & VHHOKLVFFAE & 1353.72 & 1893.90 & 1353.74 & 1893.98 \\
\hline & {$[23-40]$} & DVGSNKGAIIGLMVGGVV & 1684.92 & 2225.10 & 1684.95 & - \\
\hline
\end{tabular}


Table 3. Detected noncovalent interactions between $\mathrm{OE}$ and the tryptic fragments of $\mathrm{A} \beta(1-40)^{\mathrm{a}}$

\begin{tabular}{|c|c|c|c|}
\hline \multicolumn{2}{|c|}{$\mathrm{A} \beta$-OE tryptic digest } & \multicolumn{2}{|c|}{ OE addition after $A \beta$ tryptic digestion } \\
\hline Complete & Incomplete & Complete & Incomplete \\
\hline $\begin{array}{l}{[17-28]+\mathrm{OE}} \\
\text { obs: } 933.44(+2) \\
\text { theor: } 933.42(+2)\end{array}$ & $\begin{array}{l}{[6-28]+\mathrm{OE}} \\
\text { obs: } 1061.85(+3) \\
\text { theor: } 1061.81(+3) \\
{[6-40]+\mathrm{OE}} \\
\text { obs: } 1063.30(+4) \\
\text { theor: } 1061.26(+4)\end{array}$ & $\begin{array}{l}\text { [17-28]+OE } \\
\text { obs: } 933.44(+2) \\
\text { theor: } 933.42(+2)\end{array}$ & $\begin{array}{l}{[1-16]+\mathrm{OE}} \\
\text { obs: } 832.38(+3) \\
\text { theor: } 832.35(+3) \\
{[6-28]+\mathrm{OE}} \\
\text { obs: } 1061.86(+3) \\
\text { theor: } 1061.81(+3) \\
{[6-40]+\mathrm{OE}} \\
\text { obs: } 1063.31(+3) \\
\text { theor: } 1063.26(+3) \\
{[17-40]+\mathrm{OE}} \\
\text { obs: } 1466.76(+2) \\
\text { theor: } 1466.73(+2)\end{array}$ \\
\hline
\end{tabular}

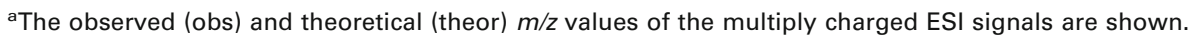

Similarly, ESI-MS analysis of the $\mathrm{A} \beta-\mathrm{OE}$ Glu-C digest yielded signals corresponding to the expected $\mathrm{A} \beta$ fragments [4-11], [12-22], and [23-40] following cleav- age at the carboxy-terminus of glutamic acid (E) residues (Table 2), and the noncovalent complexes between $\mathrm{OE}$ and the [4-11] and [12-22] A $\beta$ Glu-C fragments

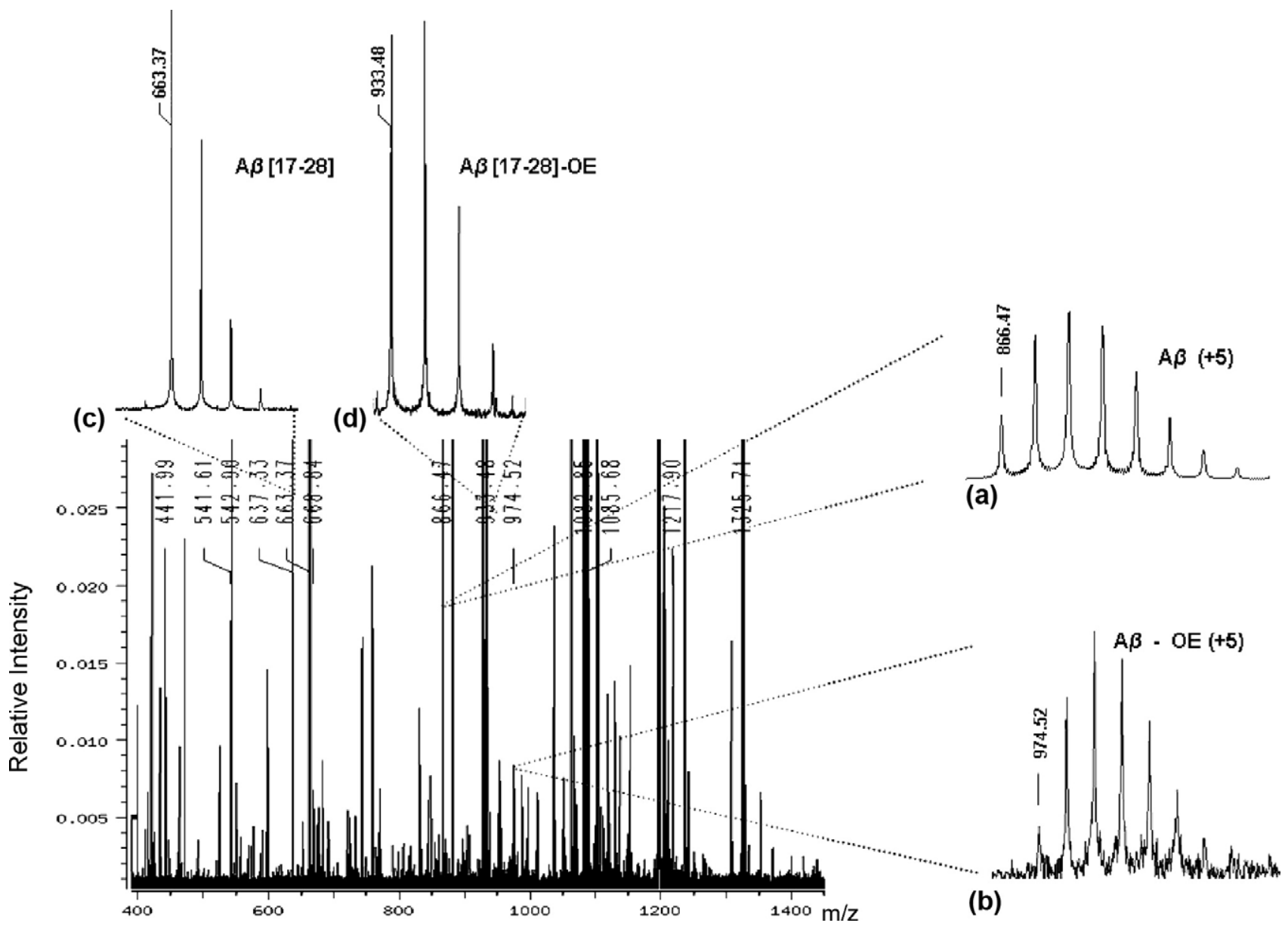

Figure 2. ESI mass spectrum of amyloid- $\beta$-peptide (1-40) in a mixture with oleuropein in a 1:1 molecular ratio, after enzymatic digestion with trypsin, acquired by a $9.4 \mathrm{~T}$ FT-ICR analyzer. The magnified regions of the spectrum correspond to (a) the +5 charged ion of the intact $A \beta$ (1-40) peptide at $m / z$ 866.47, (b) the +5 charged ion of the $\mathrm{A} \beta$-OE noncovalent complex at $\mathrm{m} / \mathrm{z} 974.52$, (c) the +2 charged ion of the [17-28] A $\beta$ tryptic fragment at $m / z 663.37$, and (d) the +2 charged ion of the noncovalent complex between [17-28] A $\beta$ tryptic fragment and oleuropein at $m / z$ 933.48. 


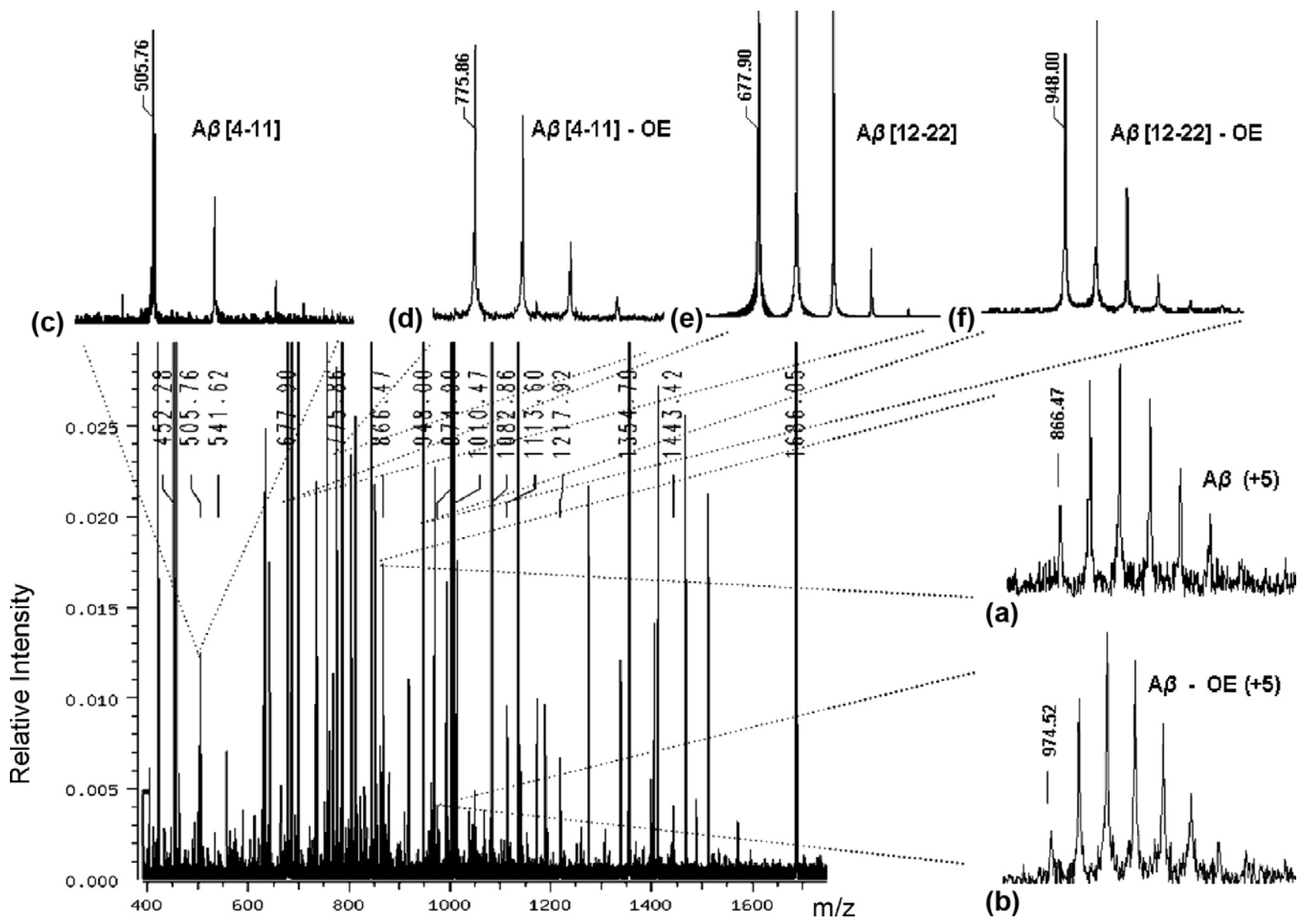

Figure 3. ESI mass spectrum of amyloid- $\beta$-peptide (1-40) in a mixture with oleuropein in a 1:1 molecular ratio, after enzymatic digestion with Glu-C, acquired by a 9.4 T FT-ICR analyzer. The magnified regions of the spectrum correspond to (a) the +5 charged ion of the intact $A \beta(1-40)$ peptide at $m / z$ 866.47, (b) the +5 charged ion of the $\mathrm{A} \beta$-OE noncovalent complex at $\mathrm{m} / \mathrm{z} 974.52$, (c) the +2 charged ion of the [4-11] A $\beta$ Glu-C fragment at $m / z 505.76$, (d) the +2 charged ion of the noncovalent complex between [4-11] A $\beta$ Glu-C fragment and oleuropein at $m / z$ 775.86, (e) the +2 charged ion of the [12-22] A $\beta$ Glu-C fragment at $m / z$ 677.90, and (f) the +2 charged ion of the noncovalent complex between [12-22] A $\beta$ Glu-C fragment and oleuropein at $m / z$ 948.00.

(Figure 3). Interactions between $\mathrm{OE}$ and the partially cleaved peptide fragments [4-40] and [12-40] (Table 4), and the added $\mathrm{A} \beta$ fragments $[(4-11)+(12-22)]$ and $[(12-$ $22)+(23-40)$ ] were also observed.
When $\mathrm{OE}$ was added into already digested $\mathrm{A} \beta$ samples with Glu-C (Table 4), ESI signals corresponded to the noncovalent interactions of $\mathrm{OE}$ with the [4-11] $\mathrm{A} \beta$ fragment, the partially cleaved peptide fragments

Table 4. Detected noncovalent interactions between OE and the Glu-C fragments of $\mathrm{A} \beta(1-40)^{\mathrm{a}}$

\begin{tabular}{|c|c|c|c|}
\hline \multicolumn{2}{|c|}{$\mathrm{A} \beta-\mathrm{OE}$ Glu-C digest } & \multicolumn{2}{|c|}{ OE addition after $\mathrm{A} \beta$ Glu-C digestion } \\
\hline Complete & Incomplete & Complete & Incomplete \\
\hline$[4-11]+O E$ & {$[4-40]+O E$} & {$[4-11]+\mathrm{OE}$} & {$[1-11]+\mathrm{OE}$} \\
\hline obs: $775.85(+2)$ & obs: $911.49(+5)$ & obs: $775.84(+2)$ & obs: $933.39(+2)$ \\
\hline \multirow[t]{3}{*}{ theor: $775.80(+2)$} & theor: $911.44(+5)$ & theor: $775.80(+2)$ & theor: $933.36(+2)$ \\
\hline & obs: $1139.10(+4)$ & & \\
\hline & theor: $1139.06(+4)$ & & \\
\hline$[12-22]+O E$ & {$[12-40]+\mathrm{OE}$} & & {$[12-40]+O E$} \\
\hline obs: $947.99(+2)$ & obs: $1187.99(+3)$ & & obs: $891.24(+4)$ \\
\hline \multirow[t]{3}{*}{ theor: $9475.95(+2)$} & theor: $1187.94(+3)$ & & theor: $891.20(+4)$ \\
\hline & & & obs: $1187.98(+3)$ \\
\hline & & & theor: $1187.94(+3)$ \\
\hline
\end{tabular}

aThe observed (obs) and theoretical (theor) $\mathrm{m} / \mathrm{z}$ values of the multiply charged ESI signals are shown. 
[1-11] and [12-40] (Table 4), and the $[(4-11)+(12-22)]$ added $\mathrm{A} \beta$ fragments.

Processing of the aforementioned mapping data derived from the two different digestion protocols utilized in this study revealed the important regions and residues for the noncovalent interaction between $\mathrm{A} \beta$ and OE. The hydrophobic sequence [17-28] of the A $\beta$ peptide, resulting from tryptic cleavage, appears to interact with $\mathrm{OE}$ in the majority of the detected fragments (Figure 2), either as a distinct fragment, or as part of a longer sequence, or even as part of noncovalently bound added fragments (Tables 2 and 3). This is further confirmed in the ESI-MS analysis of the synthetic [1228] peptide fragment, where the noncovalent interaction with $\mathrm{OE}$ is clearly observed. Comparison between the interacting tryptic and Glu-C peptide fragments indicates that the sequence [17-22] is critical for the interaction with OE (Tables 2 and 4). Furthermore, the [4-11] and [12-22] sequences of the $A \beta$ peptide derived from Glu-C digestion interact with $\mathrm{OE}$, either as a distinct fragment (Figure 3) or as part of a longer sequence. The aforementioned data suggest that the amino acid segments [17-28], [4-11], and [12-22] of the $\mathrm{A} \beta$ peptide (Figures 2 and 3 ) are responsible for its noncovalent complexation with $\mathrm{OE}$. The interaction of the chymotryptic fragment [5-19] with OE also corroborates the aforementioned indication. Thus, possibly two distinct molecules of $\mathrm{OE}$ can be bound to $\mathrm{A} \beta$ peptide, confirming the previously detected (1:2) stoichiometry of the $\mathrm{A} \beta-\mathrm{OE}$ noncovalent complex.

On the contrary, fewer interactions were detected between the ligand and the peptide fragments when $\mathrm{OE}$ was added into already digested $\mathrm{A} \beta$ samples (Tables 3 and 4). This is an indication that the detected interactions are specific and not attributed to random aggregation in the gas phase. It also demonstrates that the folding of $A \beta$ is critical for the binding and some kind of structural pocket is formed, where OE is fitted.

The fact that Glu-C proved to be more efficient than trypsin in cleaving the $\mathrm{A} \beta-\mathrm{OE}$ complex (as shown by the higher relative signal intensity of the relevant species) may yield some information about the site of the $\mathrm{OE}$ interaction. Possibly OE's binding site contains the target amino acids for tryptic cleavage, thus preventing trypsin from cleaving the peptide. Moreover, the topology of binding was confirmed by a thorough study of the interaction between $15 \mathrm{~N}$ labeled $\mathrm{A} \beta$ and $\mathrm{OE}$ using $1 \mathrm{D}$ and 2D homo- and heteronuclear NMR spectroscopy. NMR data show that the polar N-terminal fragments Ala2-Glu11 and Leu17-Ala21 undergo substantial chemical shift variations when the $\mathrm{A} \beta$ peptide is titrated with OE [39] (Supplementary material, which can be found in the electronic version of this article). Indeed, the polar group of the $\mathrm{OE}$ substrate, such as the sugar unit, would be preferably accommodated to the polar N-terminal fragment Ala2-Glu11, whereas the hydrophobic Leu17-Ala21 fragment could preferentially interact with hydrophobic units of $\mathrm{OE}$, such as the aryl ring (the NMR data will be available as a separate publication).

The findings of this study are important, complementing several reports supporting that the [14-23] A $\beta$ sequence is critical for fibrillation $[40,41]$, whereas the [16-20] sequence is essential for $A \beta-A \beta$ binding and serves as a binding sequence during $\mathrm{A} \beta$ polymerization and fibril formation [42]. It has also been proposed that structural elements in the central hydrophobic core [17-21] and at the carboxy-terminus of $A \beta$ possess a key role in controlling fibrillogenesis [34]. Moreover, it has been reported that regions [5-8] and [17-21] of the $A \beta$ hydrophobic core can prevent the neurotoxicity of aggregated $\mathrm{A} \beta[43]$.

\section{Conclusions}

This study demonstrates the multiple strength of ESI combined with FT-ICR MS. This is an extremely powerful tool for detecting noncovalent interactions of biomolecules with natural products, even if they are present in small amounts, allowing dynamic determination of all species present in the samples. The presented data indicate that $\mathrm{OE}$ interacts noncovalently with $\mathrm{A} \beta$ and its oxidized forms, with $\mathrm{A} \beta$ amino acid segments [4-11], [12-22], and [17-28] being implicated in the interaction with OE.

This information on the binding site derived from two different digestion protocols could be used to reveal the specific residues that are involved in $\mathrm{A} \beta^{\prime} \mathrm{s}$ interaction and fibrillation process. The plant-derived phytochemical under study may serve as a potential aggregation inhibitor of $\mathrm{A} \beta$ and act as protective or even more therapeutic agent against AD. Nevertheless, further confirmatory experiments were conducted with complementary instrumentation, such as $1 \mathrm{D}$ and $2 \mathrm{D}$ NMR spectroscopy. This information along with intended tandem MS experiments of the $\mathrm{A} \beta$-OE proteolytic fragments will shed light into the topology of the interaction. The presented ESI-MS-based methodology may also serve as a screening tool for evaluating new structural analogues of $\mathrm{OE}$ and facilitate the design of novel potential anti-amyloidogenic agents.

\section{Acknowledgments}

The authors gratefully acknowledge the Alexander S. Onassis Public Benefit Foundation for financing this project.

\section{References}

1. Selkoe, D. J. Alzeimer's Disease: Genotypes, Phenotypes and Treatments. Science 1997, 275, 630-631.

2. Serpell, L. C. Alzheimer's Amyloid Fibrils: Structure and Assembly. Biochim. Biophys. Acta 2000, 1502, 16-30.

3. Szabó, Z.; Jost, K.; Soós, K.; Zarándi, M.; Kiss, J.T.; Penke, B. Solvent Effect on Aggregational Properties of $\beta$-Amyloid Polypeptides Studied by FT-IR Spectroscopy. J. Mol. Struct. 1999, 480-481, 481-487.

4. Rishton, G. M.; Retz, D. M.; Tempest, P. A.; Novotny, J.; Kahn, S. Treanor, J. J. S.; Lile, J. D.; Citron, M. Fenchylamine Sulfonamide Inhibitors of Amyloid Beta Peptide Production by the Gamma-Secretase Proteolytic Pathway: Potential Small-Molecule Therapeutic Agents for the Treatment of Alzheimer's Disease. J. Med. Chem. 2000, 43, 2297-2299. 
5. Ganguly, A.K.; Pramanik, B.N.; Chen, G.; Tsarbopoulos, A. Detection of Noncovalent Complexes by Electrospray Ionization Mass Spectrometry. In Applied Electrospray Mass Spectrometry, Pramanik, B.N.; Ganguly, A.K.; Gross, M. L., Eds.; Marcel Dekker: New York, 2002; p. 361.

6. Bazoti, F. N.; Bergquist, J.; Markides, K.; Tsarbopoulos, A. Noncovalent Interaction between Amyloid- $\beta$-Peptide (1-40) and Oleuropein Studied by Electrospray Ionization Mass Spectrometry. J. Am. Soc. Mass Spectrom. 2006, 17, 568-575

7. Benavente-García, O.; Castillo, J.; Lorente, J.; Ortuño, A; Del Rio, J. A. Antioxidant Activity of Phenolics Extracted from Olea europea L. Leaves. Food Chem. 2000, 68, 457-462

8. Manna, C.; D'Angelo, S.; Migliardi, V.; Loffredi, E.; Mazzoni, O.; Morrica, P.; Galletti, P.; Zappia, V. Protective Effect of the Phenolic Fraction from Virgin Olive Oils against Oxidative Stress in Human Cells. J. Agric. Food Chem. 2002, 50, 6521-6526.

9. Saija, A.; Trombetta, D.; Tomaino, A.; Lo Cascio, R.; Princi, P.; Uccella N.; Bonina, F.; Castelli, F. "In vitro" Evaluation of the Antioxidant Activity and Biomembrane Interaction of the Plant Phenols Oleuropein and Hydroxytyrosol. Int. I. Pharm. 1998, 166, 123-133.

10. Petroni, A. Blasevich, M. Salami, M. Papini, N.; Montedoro, G. F. Galli, C. Inhibition of Platelet Aggregation and Eicosanoid Production by Phenolic Components of Olive Oil. Thromb. Res. 1995, 78, 151-160.

11. Visioli, F.; Bellosta, S.; Galli, C. Oleuropein, the Bitter Principle of Olives, Enhances Nitric Oxide Production by Mouse Macrophages. Life Sci. 1998, 62, 541-546.

12. Visioli, F.; Galli, C. Antiatherogenic Components of Olive Oil. Curr. Atheroscler. Rep. 2001, 3, 64-67.

13. Visioli, F.; Poli, A.; Galli, C. Antioxidant and Other Biological Activities of Phenols from Olives and Olive Oil. Med. Res. Rev. 2002, 22, 65-75.

14. Carluccio, M. A.; Siculella, L.; Ancora, M. A.; Massaro, M.; Scoditti, E.; Storelli, C.; Visioli, F.; Distante, A.; De Caterina, R. Olive Oil and Red Wine Antioxidant Polyphenols Inhibit Endothelial Activation: Antiatherogenic Properties of Mediterranean Diet Phytochemicals. Arterioscler. Thromb. Vasc. Biol. 2003, 23, 622-629.

15. Juven, B.; Henis, Y. Studies on the Antimicrobial Activity of Olive Phenolic Compounds. J. Appl. Bacteriol. 1970, 33, 721-732.

16. Fleming, H. P.; Walter, W. M., Jr.; Etchells, J. L. Antimicrobial Properties of Oleuropein and Products of Its Hydrolysis from Green Olives. Appl. Microbiol. 1973, 26, 777-782.

17. Bisignano, G.; Tomaino, A.; Lo Cascio, R.; Crisafi, G.; Uccella, N.; Saija, A. On the In Vitro Antimicrobial Activity of Oleuropein and Hydroxytyrosol. J. Pharm. Pharmacol. 1999, 51, 971-974.

18. Owen, R. W.; Giacosa, A.; Hull, W. E.; Haubner, R.; Würtele, G.; Spiegelhalder, B.; Bartsch, H. Olive Oil Consumption and Health: The Possible Role of Antioxidants. Lancet Oncol. 2000, 1, 107-112.

19. Trichopoulou, A.; Katsouyanni, K.; Stuver, S.; Tzala, L.; Gnardellis, C.; Rimm, E.; Trichopoulos, D. Consumption of Olive Oil and Specific Food Groups in Relation to Breast Cancer Risk in Greece. J. Natl. Cancer Inst. 1995, 87, 110-116.

20. Lee-Huang, S.; Zhang, L.; Lin Huang, P.; Chang, Y. T.; Huang, P. L. Anti-HIV Activity of Olive Leaf Extract (OLE) and Modulation of Host Cell Gene Expression by HIV-1 Infection and OLE Treatment. Biochem. Biophys. Res. Commun. 2003, 307, 1029-1037.

21. De Clercq, E. Chemotherapeutic Approaches to the Treatment of the Acquired Immune Deficiency Syndrome (AIDS). J. Med. Chem. 1986, 29 1561-1569.

22. Puel, C.; Quintin, A.; Agalias, A.; Mathey, J.; Obled, C.; Mazur, A.; Davicco, M. J.; Lebecque, P.; Skaltsounis, A. L.; Coxam, V. Olive Oil and Its Main phenolic Micronutrient (Oleuropein) Prevent InflammationInduced Bone Loss in the Ovariectomised Rat. Br. J. Nutr. 2004, 92, $119-127$.

23. Kanis, J.A. The Incidence of Hip Fracture in Europe. Osteoporos. Int. 1993, 3(Suppl. 1), 10-15.
24. Moosmann, B.; Behl, C. The Antioxidant Neuroprotective Effects of Estrogens and Phenolic Compounds Are Independent from Their Estrogenic Properties. Proc. Natl. Acad. Sci. U.S.A. 1999, 96, 8867-8872.

25. German, J. B.; Walzem, R. L. The Health Benefits of Wine. Annu. Rev. Nutr. 2000, 20, 561-593.

26. Howes, M. J. R.; Perry N. S. L.; Houghton, P. Plants with Traditional Uses and Activities, Relevant to the Management of Alzheimer's Disease and Other Cognitive Disorders. J. Phytother. Res. 2003, 17, 1-18.

27. Bastianetto, S.; Quirion, R. Natural Extracts as Possible Protective Agents of Brain Aging. Neurobiol. Aging 2002, 23, 891-897.

28. Markesbery, W. R. Oxidative Stress Hypothesis in Alzheimer's Disease. Free Radic. Biol. Med. 1997, 23, 134-147.

29. Smith, M. A.; Rottkamp, C. A.; Nunomura, A.; Raina, A. K.; Perry, G. Oxidative Stress in Alzheimer's Disease. Biochim. Biophys. Acta 2000 1502, 139-144.

30. Markesbery, W. R.; Carney, J. M. Oxidative Alterations in Alzheimer's Disease. Brain Pathol. 1999, 9, 133-146.

31. Heininger, K. A Unifying Hypothesis of Alzheimer's Disease. II. Pathophysiological Processes. Hum. Psychopharmacol. Clin. Exp. 1999, 14, $525-581$.

32. Sparks, L. D.; Martin, T. A.; Gross, D. R.; Hunsaker, J. C. 3rd. Link between Heart Disease, Cholesterol, and Alzheimer's Disease: A Review. Microsc. Res. Tech. 2000, 50, 287-290.

33. Refolo, L. M.; Malester, B.; LaFrancois, J.; Bryant-Thomas, T.; Wang, R. Tint, G. S.; Sambamurti, K.; Duff, K. E.; Pappolla M. A. Hypercholesterolemia Accelerates the Alzheimer's Amyloid Pathology in a Transgenic Mouse Model. Neurobiol. Dis. 2000, 7, 321-331.

34. Walsh, D. M.; Lomakin, A.; Benedek, G. B.; Condron, M. N.; Teplow, D. B. Amyloid Beta-Protein Fibrillogenesis. Detection of a Protofibrillar Intermediate. J. Biol. Chem. 1997, 272, 22364-22372.

35. Jarrett, J. T.; Berger, E. P.; Lansbury, P. T., Jr. The Carboxy Terminus of the Beta Amyloid Protein Is Critical for the Seeding of Amyloid Formation: Implications for the Pathogenesis of Alzheimer's Disease. Biochemistry 1993, 32, 4693-4697.

36. Shasha, B.; Leibowityz, J. On the Oleuropein, the Bitter Principle of Olives. J. Org. Chem. 1961, 26, 1948-1954.

37. Palmblad, M.; Håkansson, K.; Håkansson, P.; Feng, X. D.; Cooper, H. J.; Giannakopulos, A. E.; Green, P. S.; Derrick, P. J. A 9.4 T Fourier Transform Ion Cyclotron Resonance Mass Spectrometer: Description and Performance. Eur. J. Mass Spectrom. 2000, 6, 267-275.

38. Nilsson, S.; Wetterhall, M.; Bergquist, J.; Nyholm, L.; Markides, K. E. A Simple and Robust Conductive Graphite Coating for Sheathless Electrospray Emitters Used in Capillary Electrophoresis/Mass Spectrometry. Rapid Commun. Mass Spectrom. 2001, 15, 1997-2000.

39. Tsarbopoulos, A.; Galanakis, P.; Spyroulias, G.; Turano, P. NMR Study of the A $\beta(1-40)$ Amyloid Peptide-Natural Products Interaction towards the Prevention and Treatment of Alzheimer's Disease. In Proceedings of the 2nd Annual Meeting of EU-NMR and NMR-LIFE, Frankfurt, Germany, January 23-25, 2008 (http://www.eunmr.eu/second_annual_meeting/ eunmr2008/)

40. Kallberg, Y.; Gustafsson, M.; Persson, B.; Thyberg, J.; Johansson, J Prediction of Amyloid Fibril-Forming Proteins. J. Biol. Chem. 2001, 276 12945-12950.

41. Tjernberg, L. O.; Callaway, D. J. E.; Tjernberg, A.; Hahne, S.; Lilliehöök, K.; Terenius, L.; Thyberg, J.; Nordstedt, C. A Molecular Model of Alzheimer Amyloid Beta-Peptide Fibril Formation. J. Biol. Chem. 1999, 274, 12619-12625.

42. Tjernberg, L. O.; Näslund, L.; Lindqvist, F.; Johansson, J.; Karlström, A. R.; Thyberg, J.; Terenius, L.; Nordstedt, C. Arrest of Beta-Amyloid Fibril Formation by a Pentapeptide Ligand. J. Biol. Chem. 1996, 271, 8545-8548.

43. Penke, B.; Datki, Z.; Hetényi, C.; Molnár, Z.; Lengyel, I.; Soós, K. Zarándi, M. Molecular Pathomechanisms of Alzheimer's Disease. J. Mol. Struct. 2003, 666-667, 507-513. 